\title{
DINSAR ANALYSIS REVEALS BULGING OF AZERBAIJAN MUD VOLCANO EDIFICES BEFORE AN ERUPTION
}

\author{
Benedetta Antonielli $^{(1,2)}$, Oriol Monserrat ${ }^{(3)}$, Marco Bonini ${ }^{(4)}$, Gaia Righini ${ }^{(5)}$, Federico Sani ${ }^{(1)}$, Guido Luzi $^{(3)}$ \\ (1) Dipartimento di Scienze della Terra, Università di Firenze, via G. La Pira n.4, 50121, Firenze (Italy), \\ Email: benedetta.antonielli@unifi.it \\ (2) Tuscan Earth Science PhD Program, Earth Science Department, University of Pisa, Via S. Maria 53, 56126 Pisa (Italy) \\ (3) Centre Tecnologic de Telecomunicacions de Catalunya (CTTC), Av. Carl Friedrich Gauss, 7, Castelldefels (Spain) \\ (4) CNR, Consiglio Nazionale delle Ricerche, Istituto di Geoscienze e Georisorse, via G. La Pira 4, I-50121 Firenze (Italy) \\ ${ }^{(5)}$ ENEA, Italian National Agency for New Technologies, Energy and Sustainable Economic Development, via Martiri di \\ Monte Sole, 4, 40129, Bologna (Italy)
}

\begin{abstract}
Mud volcanism consists in the surface extrusion of gases, saline waters and mud breccias, which produce conical edifices of various sizes with morphology similar to that of magmatic volcanoes. In this work, DInSAR technique has been used to investigate the ground deformation related to the activity of Azerbaijan mud volcanoes during the period October 2003-November 2005. This work focuses on two important deformation events at the Ayaz-Akhtarma and Khara-Zira mud volcanoes. The ground deformations at mud volcanoes are generally originated by fluid pressure and volume variations in the reservoir. The observed deformation pattern is characterized by pre-eruptive inflation that reaches a cumulative value of up to $20 \mathrm{~cm}$ at Ayaz-Akhtarma in about two years. Similar pre-eruptive bulging has been observed at magmatic volcanoes, where uplift is typically associated with magma intrusion. We conclude that mud and magmatic volcanoes display some similarities in the behavior of ground deformation during pre-eruptive stages.
\end{abstract}

\section{INTRODUCTION}

Mud volcanism is a process that leads to the extrusion to the topographic surface of material originated from buried sediments, such as saline waters, gases (mostly methane), mud, and fragments or blocks of country rock. This phenomenon is typically linked to in-depth hydrocarbon traps [1], and it builds up a variety of features, the most typical of them being the conical extrusive edifices that may vary in size from centimeter-scale to a few hundred meters in height and some kilometers across.
Mud volcanoes usually occur in fold-and-thrust belts and submerged accretionary prisms $[1,2]$. The Greater Caucasus in Azerbaijan hosts the greatest number of mud volcanoes on Earth [3, 4]. Some mud volcanoes may be tall up to $400 \mathrm{~m}$, and long as much as $4-5 \mathrm{~km}$, with dimension and morphological characteristics similar to those of magmatic volcanoes. Satellite based Synthetic Aperture Radar Interferometry (InSAR) have been commonly used to investigate the ground deformation connected to the eruptive phases of magmatic volcanoes. In particular, the satellite interferometry is a powerful tool for monitoring ground deformations produced by different processes at active magmatic volcanoes. A few studies have been carried out using the InSAR technique to analyze the mud volcanoes of Azerbaijan. Reference [5] focused on the analysis of the Absheron Peninsula and the Lokbatan mud volcano, but they did not observe any large-scale movement ( $>10 \mathrm{~cm}$ line-of-sight) during the analyzed period. Reference [6] found preliminary indications of deformation in the dataset analyzed.

InSAR techniques have also been employed to explore the ground deformation associated with the LUSI mud volcano in Indonesia [7, 8, 9]. Using similar techniques, the deformation of mud volcanic systems has been analyzed using the differential interferometry (DInSAR) technique [10]. 


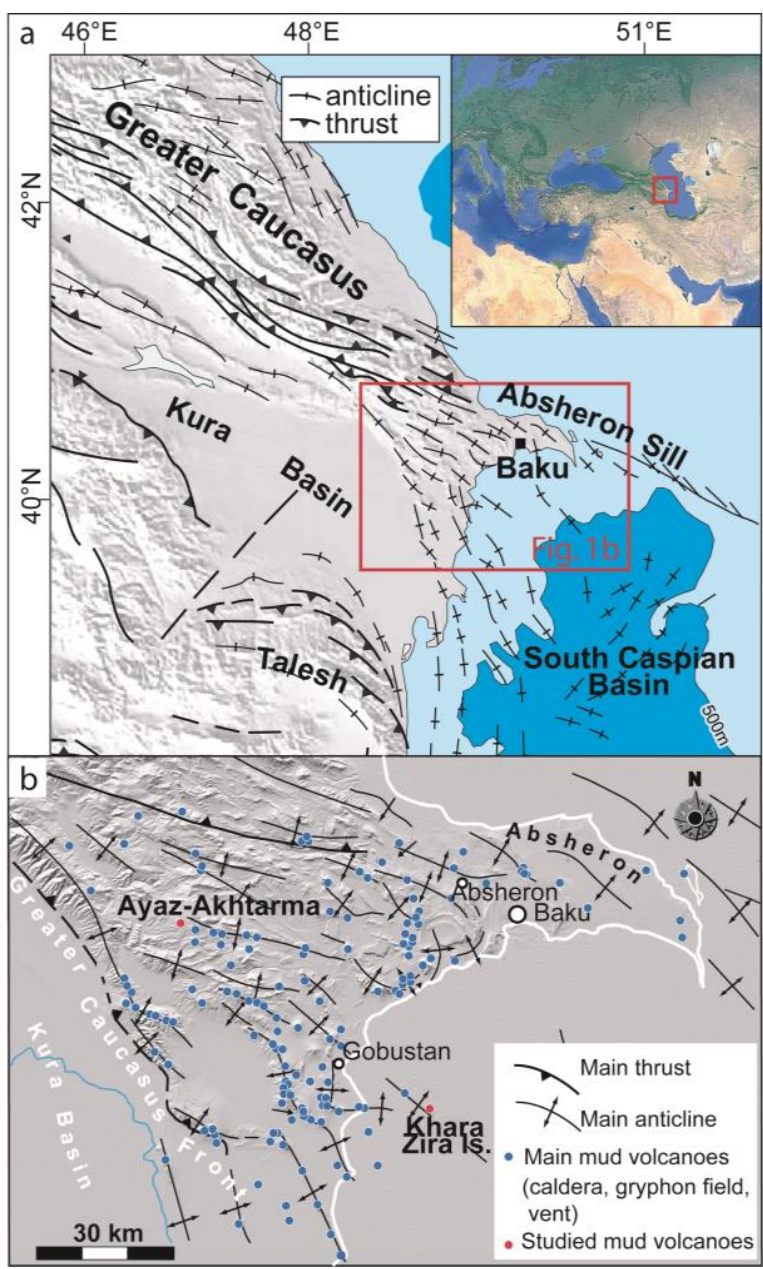

Figure 1. (a) Simplified structural sketch map of the Greater Caucasus-eastern Caspian Basin (modified from Jackson et al., 2002). (b) Main mud volcano fields around the Greater Caucasus front and Absheron area (adapted from [3, 11, 12]).

\section{GREATER CAUCASUS MUD VOLCANOES}

Mud volcanoes are closely associated with petroleum systems, and the development of overpressures in reservoir rocks is a necessary condition for triggering mud volcanism [12]. This process has often been considered to manifest subsurface intrusive processes such as mud or shale diapirism [2]. The overpressure is produced by the organogenic activity and the subsequent methane production at depth [e.g., 1]. The expansion and degassing of the methane dissolved in the mud further increases both the overpressure and buoyancy of the rising diapir [2]. Mud volcanoes and magmatic volcanoes display very similar morphologic features, and for this reason, many terms used for mud volcanism are often borrowed from the terminology of magmatic features. Mud volcanoes often localize in correspondence of anticlines where sealing layers in the fold core may efficiently trap the rising hydrocarbon fluids and readily built-up overpressures [12]. Tectonic stress provides an important source of overpressure, as highlighted by the widespread mud volcano occurrence in many active compressional belts worldwide [e.g., 12].

In the Greater Caucasus, mud volcanoes are typically associated with hydrocarbon traps in thrust anticlines $[3,13,12]$. Mud volcanoes often pierce the crest of the fold anticlines bounding the eastern Kura Basin (Baku and Apsheron Peninsula areas (Fig. 1) [3, 4], the southeast ending of the Great Caucasus (Gobustan area, Absheron Peninsula) and adjoin offshore the submerged Apsheron Sill in the South Caspian Basin (Fig. 1) [13]. Most of these mud volcanoes are thought to have begun their activity in the Pliocene around 3.5 Ma [14], thereby in close connection with the development of onshore and offshore folds that probably started to form during Early-Late Pliocene times [e.g.,14] and that are generally considered to be active.

\section{THE DINSAR DATA AND PROCESSING}

The analysis of ground deformation at volcano edifices is usually disclosed by observations of the seismic or the eruptive activity, in which case the location and timing of the events are already known. However, in the case of the Azerbaijan mud volcanoes, detailed information are lacking. Satellite based DInSAR technique has allowed us to look back on time and to document the deformation processes of four volcanoes during the period 2003 to 2005 .

\subsection{The DInSAR data analysis}

The interferometric phase contains information related to the difference on the sensor-target path at the two times. This difference can be geometrically ascribed to two main contributions: the different position of the satellite at each acquisition time, and the movement along the Line of Sight (LOS) of the measured target respectively. The former is known as the topographic component and can be removed if the topography of the measured area is known. The DInSAR phase can be also affected by other two components; the atmospheric phase component $\left(\varphi_{A t m}\right)$, that is the delay of the phase due to the different atmospheric conditions at the two acquisition times, and the phase 
noise of each measured target $\left(\varphi_{\text {Noise }}\right)$, related to the radar response changes occurred in between the two acquisitions to the target.

Finally, it has to be considered that the interferometric phases are measured modulus $2 \pi$ and in case of deformation larger than half radar wavelength, unambiguous estimate of the deformation is possible only after "unwrapping" procedure. Hence the relationship between the measured interferometric phase and the occurred movement demands the use of the following, DInSAR equation:

$$
\Delta \varphi_{\text {Int }}=\left(\varphi_{\text {Topo }}+\varphi_{\text {Mov }}+\varphi_{\text {Atm }}+\varphi_{\text {Noise }}\right) \operatorname{Mod} 2 \pi
$$

In the literature are described different approaches to solve the equation (1) $[15,16,17]$. However, these approaches were discarded for this work because all of them are based in processing large data stacks (a minimum of approximately 15 images are required). In this work, a simpler approach is based on the simultaneous analysis of small sets of interferograms where the contribution of the non-deformation components of the phase is assumed to be negligible. The first step of the applied procedure is to fully screen each interferogram in order to detect phase spatial variation located in mud volcano areas. Once a phase spatial variation is detected, the significance of the contribution of each one of the non-deformation components is evaluated by using a pairwise logic criterion [18] as briefly described here:

$\varphi_{\text {topo }}$ : This component is linearly related to the perpendicular baseline of the interferogram [19]. Hence the way to decide whether the observed phase variation is $\varphi_{\text {topo }}$ is to observe the same area in two interferograms with opposite perpendicular baseline. If the phase variation has opposite gradient, then the observed pattern is mainly due to $\varphi_{\text {topo }}$. Otherwise the $\varphi_{\text {topo }}$ contribution is discarded.

$\boldsymbol{\varphi}_{\text {Atmo }}$ : Let's assume that we observe a phase variation in an interferogram $\Delta \varphi_{21}=\varphi_{2}-\varphi_{1}$ and that the phase variation is mainly due to the atmospheric contribution of $\varphi_{1}$. Then, the same phase variation should appear in an interferogram $\Delta \varphi_{1 \mathrm{k}}=\varphi_{1}-\varphi_{\mathrm{k}}$ but with opposite sign. Therefore, analyzing different combinations of $\varphi_{1}$ and $\varphi_{2}$ makes possible the discrimination of a significant $\varphi_{\text {Atmo }}$ contribution.

$\boldsymbol{\varphi}_{\text {Noise: }}$ This contribution is evaluated for each interferogram by means of the coherence. The coherence threshold has been chosen iteratively for each interferogram and each mud volcano separately.
The final coherence threshold is based on a trade-off between the level of noise and the spatial point density, in order to obtain a reliable phase unwrapping. It is worth noting that the reliability of the unwrapped phase is qualitatively evaluated comparing the unwrapped interferogram with its corresponding wrapped version.

The phase unwrapping step consists on the determination of the absolute cycles of the phase that leads to a correct interpretation of the measured deformation. Only those interferograms with a tradeoff between coherence and spatial density have been used. This criterion limited, in our case, the use of a maximum temporal baselines of 105 days. Longer temporal baselines show poor correlation in most of the cases. The phase unwrapping have been performed by an implementation of the minimum cost flow algorithm described in [20]. To conclude, it is important to underline that the final deformation maps are represented in Line of Sight direction, i.e. the measured deformation at one point is the projection of the actual deformation along the satellite to view line.

\subsection{The used SAR dataset}

In this study a dataset of 9 ENVISAT descending images with a time span from October 2003 to November 2005 have been processed. Data have been provided by the European Space Agency (Cat-1 Project 13866). In detail, we surveyed an area of 100 $\mathrm{km}^{2}$ in which the majority of the Azerbaijan mud volcanoes (about 300) are included. The available interferometric pairs were processed by using software developed at the Centre Tecnològic de Telecomunicacions de Catalunya (CTTC). The DTM used was form the STRM (Shuttle Radar Topography Mission). A subset of 8 interferograms was selected for the analysis, which showed a good phase unwrapping and covered the entire period of observations was selected for the analysis.

\section{RESULTS}

DInSAR observations have allowed us to detect significant deformation at some volcanic edifices in the Absheron Peninsula, and in the Baku Archipelago. No dedicated monitoring networks exist, consequently, the present-day mud volcanic activity remains poorly documented, and the associated hazard is basically neglected. After a general screening of the 
used ENVISAT frame, we focused our study on the Ayaz-Akhtarma and the Khara-Zira mud volcanoes (Fig. 1b) because the deformation at these sites clearly stands out. A geological-structural field survey was carried out at the Ayaz-Akhtarma mud volcano during June 2013 to collect morphological and structural data. The results are described below.

\subsection{Ayaz-Akhtarma mud volcano}

The Ayaz-Akhtarma mud volcano is a large edifice characterized by an elliptical, flat top surface (major axis about $2700 \mathrm{~m}$ ) that is interpreted as a filled mud caldera depression [12] (Fig. 2a, b and d). Significant surface ground displacement inside the caldera is registered in the interferograms from October 2003 and November 2005 (Fig. 3), connected to a strong eruptive activity (recorded eruptions of 2005, 2006 and 2007) [21]. Assuming a purely vertical deformation, the eastern part of the volcanic edifices has lifted and the western sector has subsided, although with lower rates. This is shown in Fig. 4, where the cumulative LOS displacements for the two orthogonal cross-sections (marked in the last panel of Fig. 3) are represented.

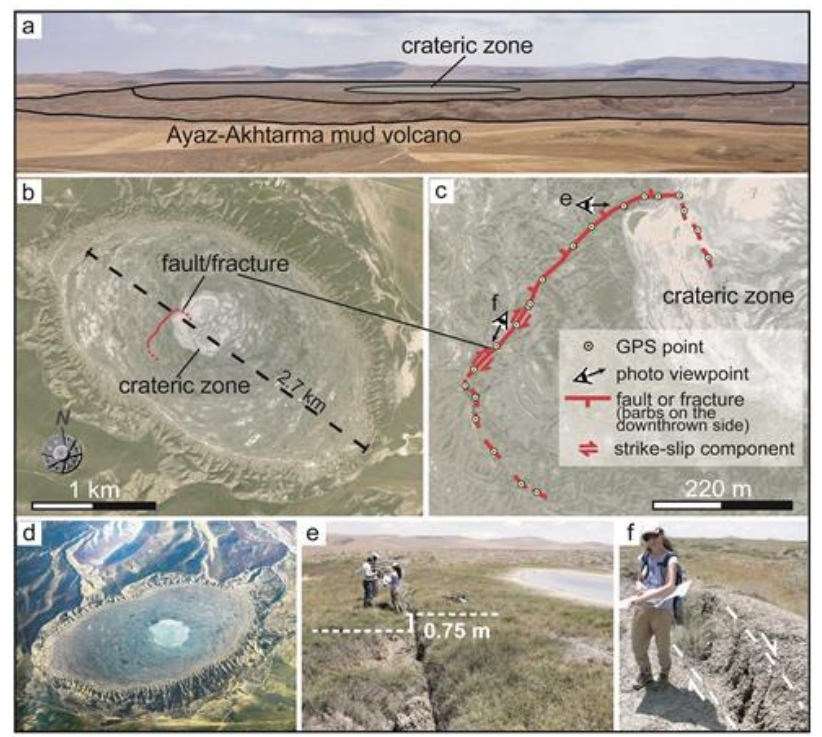

Figure 2. Ayaz-Akhtarma mud volcano. (a) Panoramic view. (b) Google Earth image (March 2004). (c)

Fracture observed during the field survey carried out in June 2013. (d) Aerial photograph. (e-f) Fault segments showing dominant vertical displacement (maximum vertical throw $\sim 1 \mathrm{~m}$ ) and en-echelon

fractures. Images in (b-d) are extracted from Google

Earth ${ }^{\circledR} ;$ http://earth.google.it/download-earth.html.
The panels on the right column of Fig. 3 represents the sum of the contributions of the interferograms. The measured ground uplift (LOS displacement) from October 2003 to November 2005, increased up to about $20 \mathrm{~cm}$ in 2 years. In the assumption of a continuous deformation, the final cumulative ground uplift is likely underestimated because it was not possible to measure the deformation for interferograms with low coherence values (JanuaryNovember 2004 and April-July 2005 interferograms, white panels in Fig. 3). From July until November 2005 the uplift has indeed increased in rate (up to 6 $\mathrm{cm}$ in 70 days) and has been focused in a specific semicircular zone showing a larger diameter in comparison to the previous interferograms (Fig. 3). This observation suggests that the zone of highest uplift probably corresponds to the center of inflation. The western area of the mud volcano is affected by a lesser subsidence which decreases in the last interferograms. Volumetric deformation rates of the order of those measured in this case may be associated with some surface brittle fracturing. In order to investigate this possibility, a geological-structural field survey was carried out in June 2013 aiming to detect and map the main fractures. The field survey allowed the identification of a ca. 600 m-long main fault/fracture zone with average direction $\mathrm{N} 42^{\circ} \mathrm{E}$ (Fig. 2c). The north-eastern part of the fracture is characterized by a normal vertical throw varying between $25 \mathrm{~cm}$ and $1 \mathrm{~m}$ (Fig. 2e). It was possible to recognize the same fault/fracture zone (observed in 2013) in the Google Earth images dating back to 2004 (Fig. 2c), thereby suggesting that fault/fracture zone has been active since 2004 . 


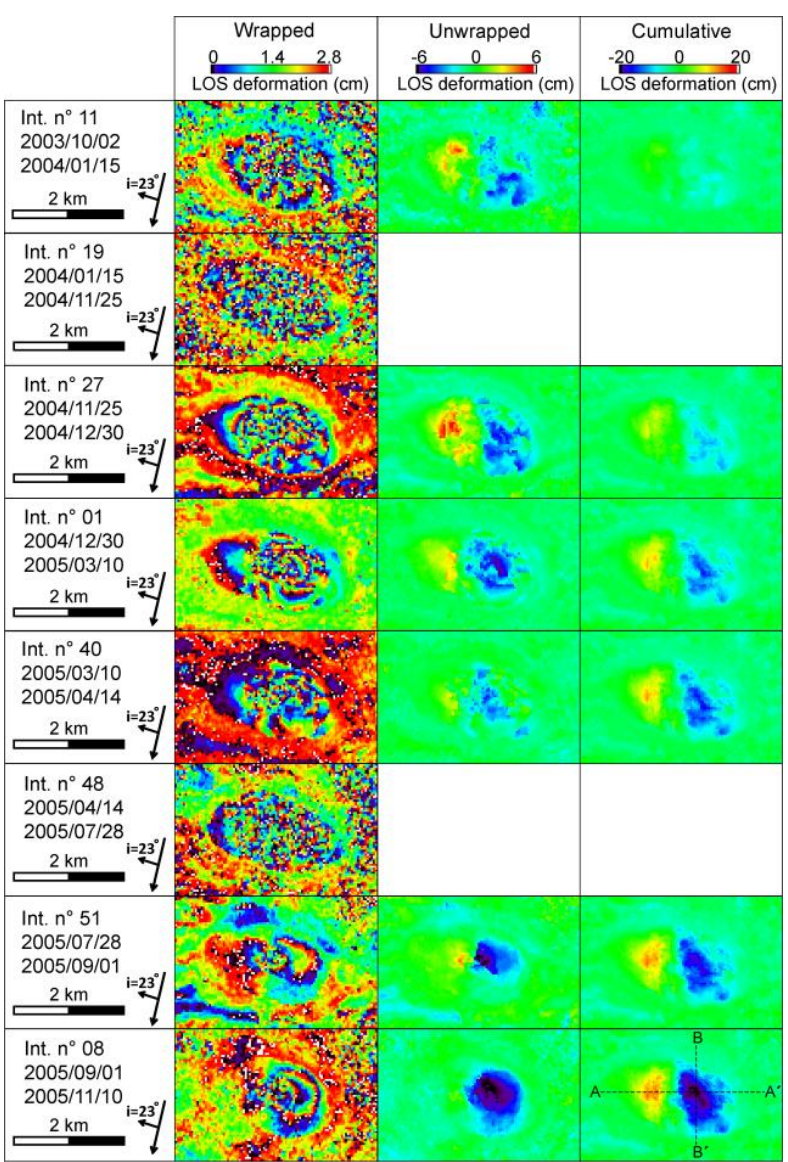

Figure 3. Wrapped (left column), unwrapped (central column) and cumulative (right column) interferograms of the Ayaz-Akhtarma mud volcano (after [10]).

Unwrapped and relative cumulative interferograms with low coherence are not reported (white panels). The mean coherence threshold for all the used

interferograms is $0.1 \pm 0.05$. Blue color and negative sign in the chromatic scale indicate uplift as the sensortarget distance decreases; red color and positive sign indicate subsidence, as the sensor-target distance increases.

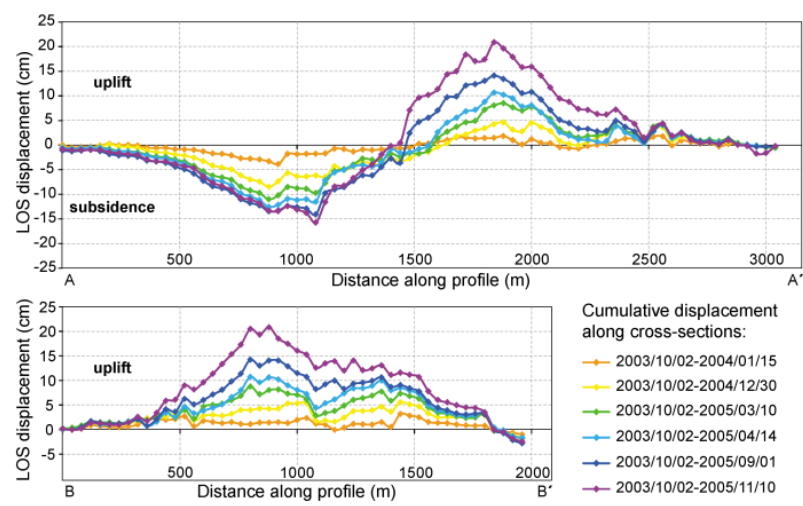

Figure 4. Observed cumulative LOS displacements along cross-sections of the Ayaz-Akhtarma mud volcano(after [10]). The traces $A-A$ ' and $B$ - $B$ ' are indicated in Fig. 3 (bottom right panel).

\subsection{Khara-Zira Island}

The Khara-Zira island occurs offshore southsouthwest of Baku and is one of the islands built by mud volcanoes in the Caspian Sea [22, 21]. The Khara-Zira island is elliptical in shape (with maximum length of $\sim 2.4 \mathrm{~km}$ ) and is topped by a rather flat surface.

According to the catalogue of recorded mud volcano eruption, a major paroxysmal phase occurred on $20^{\text {th }}$ November 2006 [21]. The time span covered by the interferograms with good coherence values (October 2003-November 2005) ends one year before the eruption and therefore it can be used to observe the initial stages of pre-eruptive deformation.

The majority of the mud volcano surface is characterized by a relative ground uplift that is detected in all the interferograms (Fig. 5, panels on the left and on center columns). The cumulative ground uplift, for the entire time span analyzed, exceeds 10 $\mathrm{cm}$ in 2 years (Fig. 6). At the north-western part of the island the displacement appears with opposite sign in two interferogram pairs, namely n.19-n.27, and n.51n.08 (Fig. 5). The two interferogram pairs share a common master or slave date. This suggests that the change of displacement sign can be the result of peculiar atmospheric conditions on two dates (25 November 2004 for the first pair, and 1 September 2005 for the second pair). Such rapid signal changes likely represent a local atmospheric disturbance, and thus may not represent actual ground displacement. 


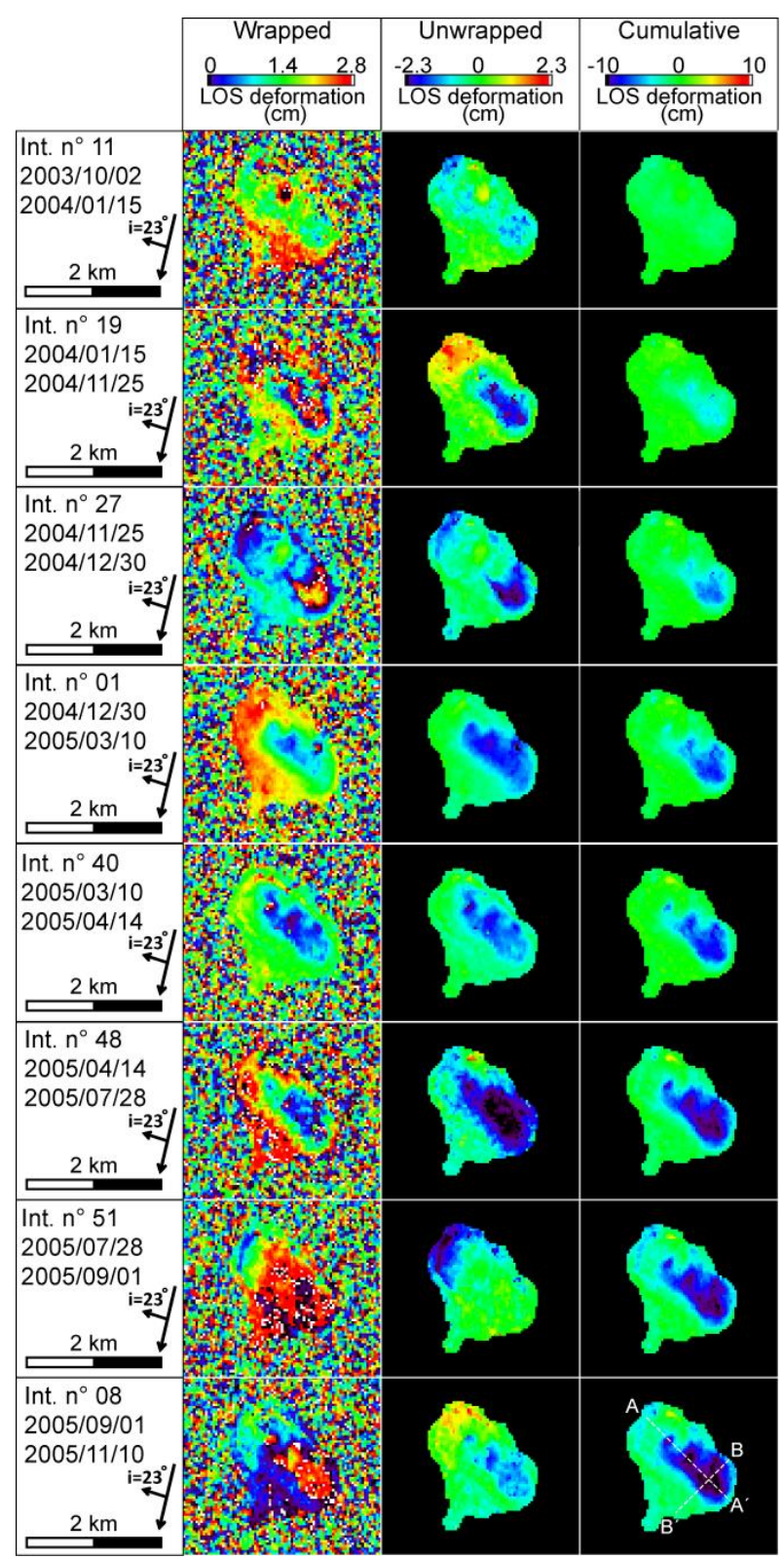

Figure 5. Wrapped (panels on the left column), unwrapped (panels on the central column) and cumulative (panels on the right column) interferograms of the Khara-Zira mud volcano (after [10]). The mean coherence threshold for all the used interferograms is $0.3 \pm 0.05$. The LOS ground displacement infers a maximum motion toward the satellite (i.e. uplift) in the south-eastern part of the mud volcano (for explanation see Figure 3 caption).
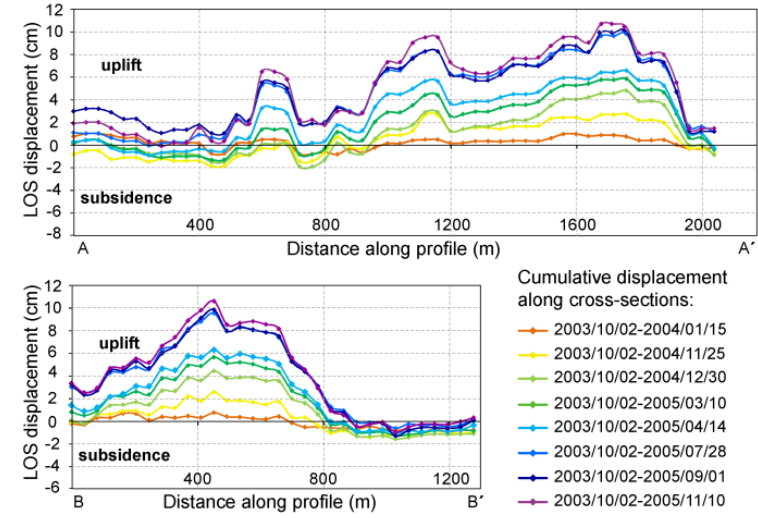

Figure 6. Observed cumulative LOS displacements along cross-sections of the Khara-Zira mud volcano (after [10]). The traces $A-A$ ' and $B-B$ ' are indicated in Fig. 5 (bottom right panel).

\section{Discussion and conclusion}

In the absence of monitoring systems and detailed historical information about mud volcanic activity, satellite-based observation could play a relevant role in assessing the superficial deformation patterns and therefore the hazards related to mud volcanoes.

The analyzed interferograms showed two deformation events that can be directly related to pre-eruptive deformation phases at two mud volcanic edifices: the Ayaz-Akhtarma and the Khara-Zira Island. In particular, the deformation phases are connected to the 2005 eruptive event of the Ayaz-Akhtarma mud volcano, and to the activity up to one year before the eruption of the Khara-Zira Island on 26 November 2006. The deformation shows a relative uplift of the main active zone of the mud volcano for both examined cases. The deformation of both the AyazAkhtarma and the Khara-Zira Island mud volcanoes is likely linked to an increase of internal pressure. This hypothesis is supported by the fact that it has long been recognized that mud volcano activity is driven by internal fluid pressure changes [e.g., 2, 23, 24, 22]. It is worth noting that at least a part of the mud volcano undergoes bulging before an eruption. At the AyazAkhtarma mud volcano, the deformation is characterized by two adjacent zones of local uplift and subsidence. The uplift phenomenon predominates and continuously grows in intensity, especially in the last two interferograms (Fig. 3). In general, the eruption is accompanied by a clear signal of subsidence due to the discharge of material and release of gas pressure, as occur at the LUSI mud volcano [e.g., 7, 8, 9] and at magmatic volcanoes [e.g., 25, 26]. By contrast, a 
nearly continuous uplift of the main active zone is observed at the Ayaz-Akhtarma mud volcano, probably because the eruption (associated with subsidence) occurred after the date of the last interferogram (10 November 2005).

The simultaneous presence of subsidence and uplift has been reported during the eruption of LUSI mud volcano [7]. In this case, the subsidence is caused by the removal of mud from the subsurface and by the collapse of the overburden, while the uplift aligns with the Watukosek fault system. The fault/fracture system plays a fairly important role in producing the deformation pattern at the Ayaz-Akhtarma. Specifically, this system downfaults the sector affected by the highest subsidence, which could correspond to a deflation zone, and may be a response to a redistribution of fluids. The fault/fracture zone may thus represent a shallow structure originated to accommodate differential ground displacement.

Uplift-subsidence patterns have also been observed in magmatic volcanoes, where uplift is typically associated with magma intrusion in the shallow crust or with hydrothermal fluid injection and circulation. In several large calderas and magmatic volcanoes, such as Yellowstone and Campi Flegrei, volcanic uplift can generate complex patterns of ground deformation, which may be concurrent with the presence of areas of subsidence [e.g., 27, 28]. The uplift-subsidence patterns identified at the Ayaz-Akhtarma show some similarities to those observed in the Yellowstone caldera, where the area affected by subsidence could correspond to a deflation zone and the brittle fracturing/faulting accommodates the differential volumetric variations [28]. Similarly, reference [29] identified deformation patterns of the Cerro Blanco/Robledo Caldera during a resting phase period. There, the caldera subsides with decreasing velocity while a positive velocity field is detected in the northwestern part of the system outside the caldera.

To conclude, important deformation events, driven by fluid pressure and volume variations, can happen in connection with main eruptions. The pre-eruptive deformation consists of marked uplift and occasional minor subsidence that is probably related to subsurface redistribution of pressurized fluids. Ground uplift has been detected to manifest up to one year before the eruption (e.g., Khara-Zira Island). The similarities in the time-space evolution of ground deformation evidenced for the studied mud volcanoes of Azerbaijan thus strengthen the notion that similar processes may be expected to govern both igneous and mud volcano systems. The present study indicates that satellite radar interferometry represents a suitable tool for studying mud volcano activity, and the results contribute to a wider understanding of the processes driving ground deformation at mud volcanoes.

\section{References}

1. Higgins, G., Saunders, J.B., (1974). Mud volcanoes e their nature and origin. In: Jung, P., et al. (Eds.), Contributions to the Geology and Paleobiology of the Caribbean and Adjacent Areas. Verh. Aturforsch. Ges., vol. 84(1), pp. 101-152.

2. Brown, K. M., (1990). The nature and hydrological significance of mud diapirism and diatremes for accretionary systems. J. Geophys. Res. 95, 89698982.

3. Jakubov, A. A., Ali-Zade, A. A., Zeinalov, M. M., (1971). Mud Volcanoes of the Azerbaijan SSR. Atlas (in Russian), Azerbaijan Academy of Sciences, Baku.

4. Guliyev, I. I., Feizullayev, A. A., (1997). All about mud volcanoes, Bafta Press, Baku, Azerbaijan.

5. Mellors, R.J., Bunyapanasarn, T., Panahi, B., (2005). Insar Analysis of the Absheron Peninsula and Nearby Areas, Azerbaijan. Mud Volcanoes, Geodynamics and Seismicity, NATO Science Series, Volume 51, pp 201-209.

6. Hommels, A., Scholte, K.H., Munoz-Sabater, J.,.Hanssen R.F, Van der Meer, F.D., Kroonenberg S.B., Aliyeva, E., Huseynov, D., Guliev, I., (2003). Preliminary Aster and InSAR imagery combination for mud volcano dynamics, Azerbaijan. International Geoscience and Remote Sensing Symposium 3, III: 1573-1575.

7. Abidin, H., Z., Davies, R., J., Kusuma, M., A., Andreas, H., Deguchi, T., (2009). Subsidence and uplift of Sidoarjo (East Java) due to the eruption of the Lusi mud volcano (2006present). Environ Geol, 57:833-844, DOI 10.1007/s00254-008-1363-4.

8. Fukushima, Y., Mori, J., Hashimoto, M., Kano, Y., (2009). Subsidence associated with the LUSI mud eruption, East Java, investigated by SAR interferometry. Marine and Petroleum Geology $26,1740-1750$ 
9. Rudolph, M. L., Shirzaei, M., Manga, M., Fukushima, Y., (2013). Evolution and future of the Lusi mud eruption inferred from ground deformation. Geophysical Research Letters, Vol. 40, 1-4, Doi:10.1002/Grl.50189.

10. Antonielli, B., Monserrat, O., Bonini, M, Righini, G, Sani, F, Luzi G, Feyzullayev, A.A., Aliyev, C. S., (2014). Pre-eruptive ground deformation of Azerbaijan mud volcanoes detected through satellite radar interferometry (DInSAR). Tectonophysics, doi 10.1016/j.tecto.2014.10.005.

11. Jackson, J., Priestley, K., Allen, M., Berberian, M., (2002). Active tectonics of the South Caspian Basin. Geophysical Journal International, 148, 214-245.

12. Bonini, M., (2012). Mud volcanoes: indicators of stress orientation and tectonic controls. Earth Sci. Rev. 115, 121-152.

13. Stewart, S. A., Davies, R.J., (2006). Structure and emplacement of mud volcano systems in the South Caspian Basin. AAPG Bulletin, 90, 771786.

14. Yusifov, M., Rabinowitz, P. D., (2004). Classification of mud volcanoes in the South Caspian Basin, offshore Azerbaijan. Marine and Petroleum Geology, 21, 965-975.

15. Ferretti, A., Prati, C., Rocca, F., (2001). Permanent scatterers in SAR interferometry. IEEE Trans. Geosci. Remote Sens., 39(1), pp. 8-20.

16. Hooper, A., Zebker, H., Segall, P., Kampes, B., (2004). A new method for measuring deformation on volcanoes and other natural terrains using InSAR persistent scatterers. Geophysical Research Letters, vol. 31, no. 23, December 2004.

17. Biescas, E., Crosetto, M., Agudo, M., Monserrat, O., Crippa, B., (2007). Two radar interferometric approaches to monitor slow and fast land deformations. Journal of Surveying Engineering, 133, 66-71.

18. Massonnet, D., Feigl, K. L., (1998). Radar interferometry and its application to changes in the earth's surface. Rev. Geophys. 36,441-500.

19. Hanssen, R., (2001). Radar interferometry: data interpretation and error analysis (Vol. 2). Springer.
20. Costantini, M., (1998). A novel phase unwrapping method based on network programming. IEEE Transactions on Geoscience and Remote Sensing, 36(3), 813-821.

21. Aliyev, A.A., Guliyev, I.S., Rahmanov, R.R., (2009). Catalogue of recorded of mud volcano eruptions of Azerbaijan (1810-2007). Second Edition. 'Nafta-Press' Publishing-House, Baku, 109 pp.

22. Mellors, R.J., Kilb, D., Aliyev, A., Gasanov, A., Yetirmishli, G., (2007). Correlations between earthquakes and largemud volcano eruptions. $J$. Geophys. Res.112, B04304, doi: 10.1029/2006JB004489.

23. Dimitrov, L. I., (2002). Mud volcanoes - the most important pathway for degassing deeply buried sediments. Earth-Science Reviews 59, 49-76.

24. Davies, R.J., Swarbrick, R.E., Evans, R.J., Huuse, M., (2007). Birth of a mud volcano: East Java, 29 May 2006. Geological Society of America Today 17, 4-9.

25. Amelung, F., Jónsson, S., Zebker, H., Segall, P., (2000). Widespread uplift and 'trapdoor' faulting on Galápagos volcanoes observed with radar interferometry. Nature, v. 407, p. 993-996, doi: $10.1038 / 35039604$.

26. Jay J., Costa F., Pritchard M., Larac L., Singer B., Herrin J., (2014). Locating magma reservoirs using InSAR and petrology before and during the 2011-2012 Cordón Caulle silicic eruption. Earth and Planetary Science Letters 395, 254-266.

27. Wicks, C., Thatcher, W., Dzurisin, D., (1998). Migration of fluids beneath Yellowstone caldera inferred from satellite radar interferometry: Science, v. 282, p. 458-462, doi: 10.1126/science.282.5388.458.

28. Chang, W., Smith, R.B., Wicks, C., Farrell, J.M., Puskas, C.M., (2007). Accelerated uplift and magmatic intrusion of the Yellowstone caldera, 2004 to 2006. Science, v. 318, p. 952-956, doi: $10.1126 /$ science 1146842 .

29. Brunori, C.A., Bignami, C., Stramondo, S., Bustos, E., (2013). 20 years of active deformation on volcano caldera: Joint analysis of InSAR and AInSAR techniques. International Journal of Applied Earth Observation and Geoinformation 23, 279-287. 